I should like to suggest that there is no need for precipitate action, that the College has time to negotiate with the DHSS and the Regions, taking into account the recommendations of its Special
Committee and the report of the Data Protection Committee (1978), and that no harm will come to patients if MHE forms continue to be completed while negotiations are taking place.

\title{
CORRESPONDENCE
}

\section{PSYCHIATRIC EXAMINATIONS IN THE UNITED STATES AND CANADA}

DeAr Sir,

I think that Dr Joseph Berger's article comparing psychiatric examinations in the United States and Canada (Bulletin, October 1978) is outdated and misleading. The Canadian written examination changed completely to the 'objective' type (multiple choice questions) in 1976. Dr Berger has relied heavily on his impressions rather than on factual information, and although it may have seemed to him that the Canadian multiple choice examination was 'too heavily basic science oriented' the proportion of questions related to basic science is limited; for example, in 1978 basic science questions constituted about 15 per cent of all the questions, with the same percentage devoted to questions about psychodynamics and psychotherapy." Dr Berger believes that 'a clinical examination is no longer the place to test text-book knowledge'. Since text-books these days are so comprehensive, it would be difficult to conduct a clinical examination that did not require of the candidate some knowledge of what is recorded in text-books. However, if Dr Berger is implying that basic science information or abstruse academic information is sought in the clinical examination, he is mistaken: examiners are specifically instructed not to ask questions that do not refer directly to the problems posed by the examined patient, or to the practical problems of treatment posed by patients described in clinical vignettes.

The impressionistic nature of Dr Berger's article is strongly apparent in many of his statements. It 'seems' to him that the pool of Canadian examiners is small. In fact, it is potentially large, since new examiners are recruited and others retired every year. As for their 'highly variable' quality, I think Dr Berger would agree that without supporting evidence this is a gratuitous judgement. In fact, the examiners themselves are regularly assessed for their thoroughness and fairness. When Dr Berger states that in Canada the candidate is seen as a student, he is definitely wrong. Before the candidate is permitted to sit the examinations he must have a report from the Director of his residency training program stating that he is fit to function as a specialist psychiatrist. The problem for the examiners is that the candidates so often see themselves only as students in spite of the communications they get to the contrary from their colleague-teachers and from the Canadian Royal College. Clinical examiners are specifically instructed to try and put candidates at ease. A candidate's interview technique is judged not only as it pertains to the inquiry and conduct of the mental status examination but also as it affects his ability to be therapeutic with the patient he is assessing. For example, a candidate who pushes ahead with the inquiry completely disregarding indications that the patient is distressed or needs reassurance is marked down. It is common for examiners to ask such questions as 'Doctor —-, if this (the patient examined) had been a patient you had seen in your office, what parts of your assessment would you have liked to follow further?'; or 'Dr , if your preferred plan of management did not produce the improvement you hoped for, what else would you have considered?'.

Half my psychiatric training was done in Canada and half in the United States. I have taught residents in both the US and Canada. Although it may be true that American trainees are more adept at speculating about psychodynamic formulations, I believe that the Canadian residents I have seen are more comprehensively trained clinicians than their American counterparts, and potentially just as good as psychotherapists. I hope that those British trainees who plan to sit the Canadian examinations will see $\mathrm{Dr}$ Berger's article for what it is-one psychiatrist's impression-and not regard it as a source of accurate information.

$$
\text { P. C. S. HOAKEN, }
$$

Member, Examining Board in Psychiatry, Royal College of Physicians and Surgeons (Canada) 1975-78.

Queen's University, Kingston, Ontario.

Personal Communication, Dr William G. Dewhurst, Executive Director, Royal College Test Committee (Psychiatry). 